Communications in Physics, Vol. 26, No. 4 (2016), pp. 345-350

DOI: $10.15625 / 0868-3166 / 26 / 4 / 9004$

\title{
THE SENSITIVITY OF ANIMAL CELLS SENSITIZED WITH BILIRUBIN UNDER IRRADIATION OF SPECTRAL BLUE AND GREEN BAND
}

\author{
O. A. KOZLENKOVA ${ }^{1, \dagger}$, L. G. PLAVSKAYA ${ }^{1}$, A. V. MIKULICH ${ }^{1}$, I. A. LEUSENKO ${ }^{1}$, \\ A. I. TRETYAKOVA ${ }^{1}$, V. YU PLAVSKII ${ }^{1}$, J. GAO $^{2}$, D. XIONG ${ }^{2}$ AND X. WU ${ }^{2}$ \\ ${ }^{1}$ Laboratory of Organic Heterogeneous Media, \\ B. I. Stepanov Institute of Physics, National Academy of Science of Belarus, Belarus \\ ${ }^{2}$ Suzhou Institute of Biomedical Engineering and Technology, \\ Chinese Academy of Sciences, China \\ ${ }^{\dagger}$ E-mail: olga.kozlenkova@gmail.com \\ Received 14 December 2016 \\ Accepted for publication 17 February 2017
}

\begin{abstract}
It has been shown that optical irradiation with LED sources of an emission band maximum at about $465 \mathrm{~nm}$ and $520 \mathrm{~nm}$ has substantially identical damaging effects on animal cells in culture that are in a logarithmic growth phase and pre-incubated with pigment. Photobiological effect is caused by photodynamic processes involving singlet oxygen generated by triplet excited sensitizer. Mono-exponential type dependence of cell survival on irradiative energy dose indicates that it is bilirubin that acts as a sensitizer but not its photoproducts. The inclusion of bilirubin in the cells where it is primarily localized in the mitochondria, is accompanied by a multiple enhanced photochemical stability compared to pigment molecules bound with albumin.
\end{abstract}

Keywords: hyper-bilirubinemia, bilirubin, photosensitizer, cell viability, MTT-test, phototherapy, singlet oxygen.

Classification numbers: 87.50.W, 87.64.-t.

\section{INTRODUCTION}

The development of syndrome of neonatal hyperbilirubinemia (jaundice) is caused by excessive accumulation in the blood, as well as in subcutaneous fat of gall pigment (breakdown product of normal heme catabolism) -Z, Z-bilirubin IX $\alpha$, due to its overproduction and/or low excretion rate from the body. The main and most common method for treating neonatal hyperbilirubinemia is phototherapy, which bases on exposure of body surface to the radiation of spectral emission band which corresponds to the absorption band of bilirubin [1-6]. It is believed [7-11]

(C)2016 Vietnam Academy of Science and Technology 
that photo-isomerization processes of the pigment play a considerable role in reducing the bilirubin level in newborns under irradiation, basing on the formation of its structural isomers that are more hydrophilic compounds than the native bilirubin and quickly eliminated from the body. In addition to photo-isomerization, self-sensitized photolysis of bilirubin involving singlet oxygen also contributes to the reduction of bilirubin level [12]. At the same time, one cannot exclude that the singlet oxygen generated by triplet excited bilirubin, will cause photodynamic damage to other vital structures of molecular and cell organelles. This indicates the need to investigate sensitizing effect of bilirubin and its photoproducts on important biological structures to develop the measures for reducing possible side effects of the action of light during phototherapy. In recent years, the urgency of this problem is even more acute in connection with the applications for the treatment of neonatal hyperbilirubinemia by new light sources based on high-brightness LEDs that are variable over a wide range in intensity and wavelength within the spectral absorption band of pigment [7-11].

This work presents the comparative studies of the photostability of bilirubin in cells and in a complex with albumin as well as the study of the sensitizing mechanism of pigment-incubated cells in culture upon the irradiation with LED sources of a spectral blue and green band.

\section{MATERIALS AND METHODS}

Photostability of bilirubin was investigated in minimal essential medium (MEM) (with $10 \%$ bovine serum), in which bilirubin is in a complex with albumin, as well as in kidney cells of an African green monkey BGM in a logarithmic growth phase. The cells were grown in disposable Petri dishes in a nutrient MEM with $10 \%$ bovine serum at $37^{\circ} \mathrm{C}$ and a $5 \% \mathrm{CO}_{2}$ incubator. The cellular monolayers were preincubated with bilirubin in a concentration of $40 \mathrm{mM}$ for 2 hours, and then exposed to radiation of LED sources of an emission band maximum at about $465 \mathrm{~nm}$ or 520 $\mathrm{nm}$. Bilirubin photostability was evaluated spectrophotometrically by comparing the absorbance of the bilirubin solution extracted from the cells using DMSO immediately after irradiation with the LED source and un-irradiated cells. MTT-test was used as a criterion for the metabolic cell activity assessment.

\section{RESULTS AND DISCUSSION}

Studies have shown that bilirubin can have a sensitizing effect on the cells (as manifested in the reduction of cell viability) when excited by optical radiation at wavelength $\lambda=465 \mathrm{~nm}$ and $\lambda$ $=520 \mathrm{~nm}$. It is found that the biological effect induced by the light (photobiological effect) in the presence of bilirubin depends on the physiological state of the cells, the dose of incident radiation and the concentration of photosensitizer. Changing the power density of light in 3-4 times with appropriate compensation of energy dose by the irradiation time has practically no influence on the photobiological effect (Table 1). Adding a quencher of singlet oxygen (sodium azide) into the cells culture with the sensitizer significantly reduces the damaging effect of light towards the cells. This is indicated by the MTT-test data presented in Table 1.

One can see that the fraction of viable cells (relative to control cell group) sensitized with bilirubin is $\gamma=(45.5 \pm 1.6) \%$, in the absence of other additives under the irradiation $(\mathrm{P}=20$ $\left.\mathrm{mW} / \mathrm{cm}^{2}, \mathrm{t}=5 \mathrm{~min}\right)$. Under the same irradiative conditions for the cells in the presence of 5 $\mathrm{mM}$ of sodium azide, the fraction of viable cells is significantly increased to $\gamma=(97.9 \pm 5.7) \%$. 
Table 1. Effect of sodium azide on photosensitized bilirubin cell damage in the conditions of constant light exposure dose of energy $(\lambda=465 \mathrm{~nm})$ by varying the time and power density of incident radiation.

\begin{tabular}{|l|c|c|c|c|}
\hline \multicolumn{1}{|c|}{ Parameters } & Control group & \multicolumn{3}{|c|}{ Experimental group } \\
\hline $\begin{array}{l}\text { The power density of incident radiation, } \\
\mathrm{mW} / \mathrm{cm}^{2}\end{array}$ & 0 & 20 & 10 & 5 \\
\hline Exposure time, min & 0 & 5 & 10 & 20 \\
\hline Energy dose, $\mathrm{J} / \mathrm{cm}^{2}$ & 0 & 6 & 6 & 6 \\
\hline $\begin{array}{l}\text { Percentage of viable cells, incubated for } \\
2 \text { hours with } 40 \mu \mathrm{M} \text { bilirubin, } \%\end{array}$ & $100 . \pm 7.5$ & $45.5 \pm 1.6$ & $50.0 \pm 6.4$ & $48.7 \pm 12.5$ \\
\hline $\begin{array}{l}\text { Percentage of viable cells, incubated for } \\
2 \text { hours with } 40 \mu \mathrm{M} \text { bilirubin and } 5 \mathrm{mM} \\
\text { sodium azide, } \%\end{array}$ & $100.0 \pm 13.5$ & $97.9 \pm 5.7$ & $91.2 \pm 10.4$ & $90.2 \pm 1.0$ \\
\hline
\end{tabular}

Thus, sodium azide actually blocks the destruction of the cells sensitized with bilirubin. This fact is evidence of the decisive role of singlet oxygen in the mechanism of photodegradation of the cells sensitized with bilirubin. Also the addition of sodium azide in the culture medium prior to the irradiation reduces in some degree bilirubin discoloration. Thus, singlet oxygen plays a determining role in the photochemical processes. In the absence of bilirubin, as well as in case of the incubation of cells with bilirubin $(B R=40 \mu \mathrm{M})$ without light exposure, the effect is extremely low.

It is well known [13-15] that the lipophilic bilirubin readily soluble in lipids of cell membranes can penetrate and accumulate in the mitochondria. For this reason, the high concentration of bilirubin in the mitochondria, even in dark conditions, may alienate respiration and oxidative phosphorylation in them, induce apoptosis, disrupt protein synthesis and cause other toxic effects. As already mentioned, at the chosen bilirubin concentration ( $40 \mu \mathrm{M}$ in culture medium of) in dark conditions no appreciable effect on the survival of kidney cells of African green monkey BGM has been observed. Nevertheless, these results indirectly confirm the localization of bilirubin in mitochondrial structures, since pre-incubation of cells with bilirubin greatly affects the structure of formazan crystals formed in the mitochondria of living cells for the MTT-test. Pictures (Fig. 1) obtained at the same magnification $\left(40^{X}\right)$ clearly show that after incubation of the cells with bilirubin, formazan crystals become significantly larger (Fig. 1B) in comparison with the control intact cells (Fig. 1A). Irradiation of the cells with bilirubin significantly affected cell viability, as evidenced by low packing density of formazan crystals formed in the mitochondria (Fig. 1D). Thus in the absence of irradiation, the cells with bilirubin (Fig. 1C) have practically no effect on the arrangement density of the mentioned crystals. 


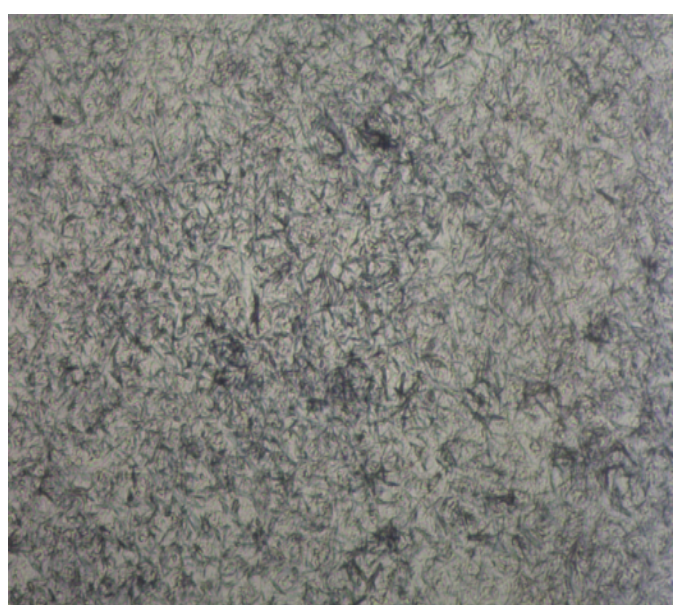

(A)

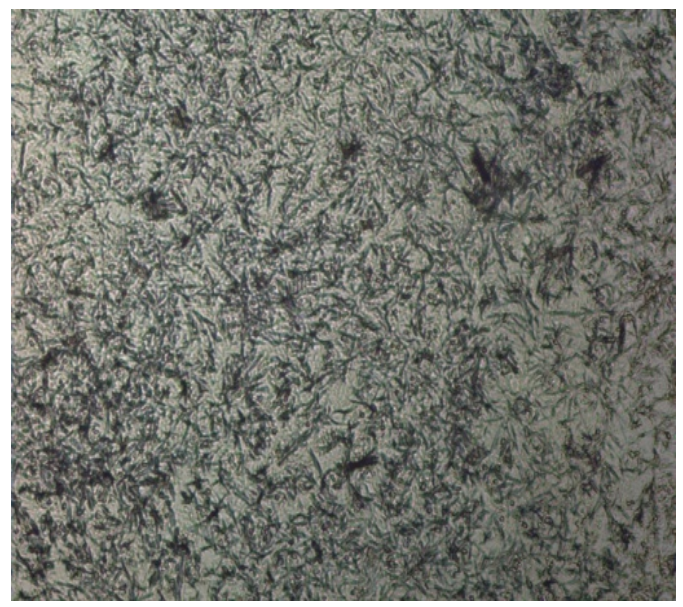

(C)

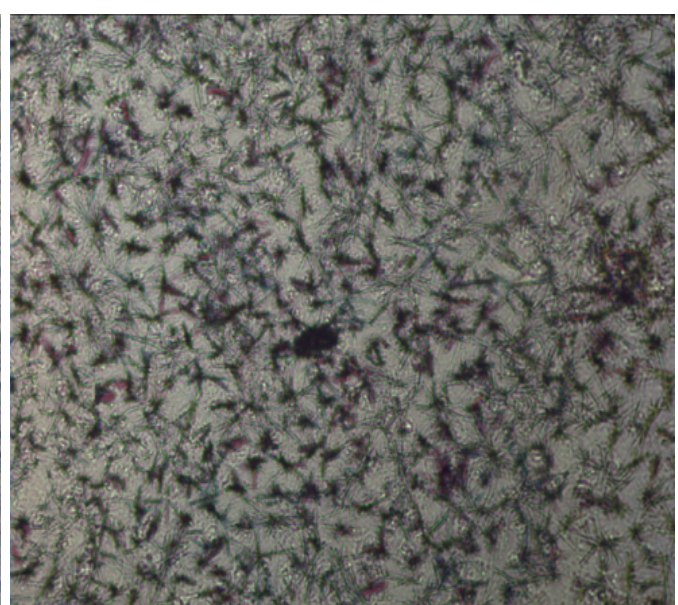

(B)

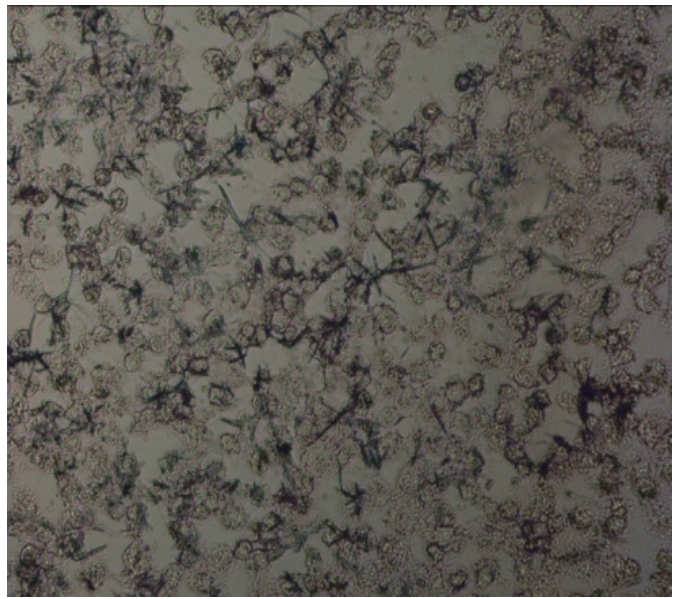

(D)

Fig. 1. Effect of bilirubin and light irradiation $\left(\lambda_{e x}=465 \mathrm{~nm}, \mathrm{P}=10 \mathrm{~mW} / \mathrm{cm}^{2}, \mathrm{t}=10\right.$ $\min )$ on the structure of crystals of formazan formed in the mitochondria of metabolically active cells (A) - cells in the absence of bilirubin and without irradiation (control); (B) - cells with bilirubin and without irradiation; (C) - irradiated cells in the absence of bilirubin; (D)- irradiated cells with bilirubin.

Using a LED source of an emission band maximum at about $465 \mathrm{~nm}$ or $520 \mathrm{~nm}$, the dependence of cell survival on energy dose upon irradiation for the cells with bilirubin is a monoexponential function (Fig. 2). This indicates that it is bilirubin that acts as a sensitizer but not its photoproducts. Another unique feature of these curves is that practically identical photobiological effects were obtained for the irradiation at $465 \mathrm{~nm}$ band in which the absorption spectrum of bilirubin-albumin complex is maximal, and for the irradiation at $520 \mathrm{~nm}$ band which corresponds to the long-wavelength slope of the specified spectrum. Apparently, it should be stated about sharp 
changes in the spectral characteristics of bilirubin upon its binding to cellular organelles because of structural rearrangements of tetrapyrrole due to changing microenvironment.

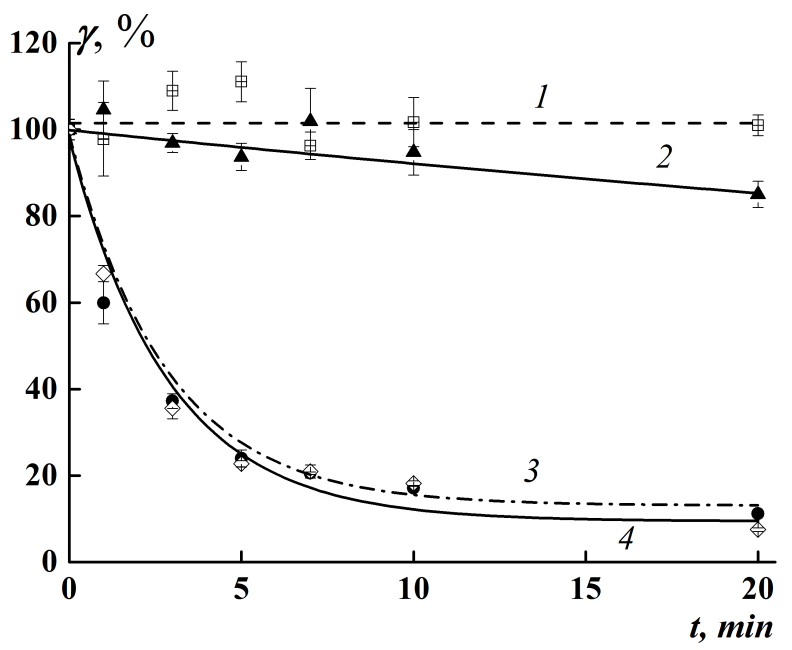

Fig. 2. The dependence of viable cells percentage sensitized with bilirubin on the irradiation time by LED sources of an emission band maximum at $\lambda_{e m}=465 \mathrm{~nm}$ (curve 2,3) and $\lambda_{e m}=520 \mathrm{~nm}$ (curve 1,4): 1,2 - cells without bilirubin; 3,4 - cells sensitized with bilirubin $(b=40 \mu \mathrm{M})$, power density $\mathrm{P}=20 \mathrm{~mW} / \mathrm{cm}^{2}$.
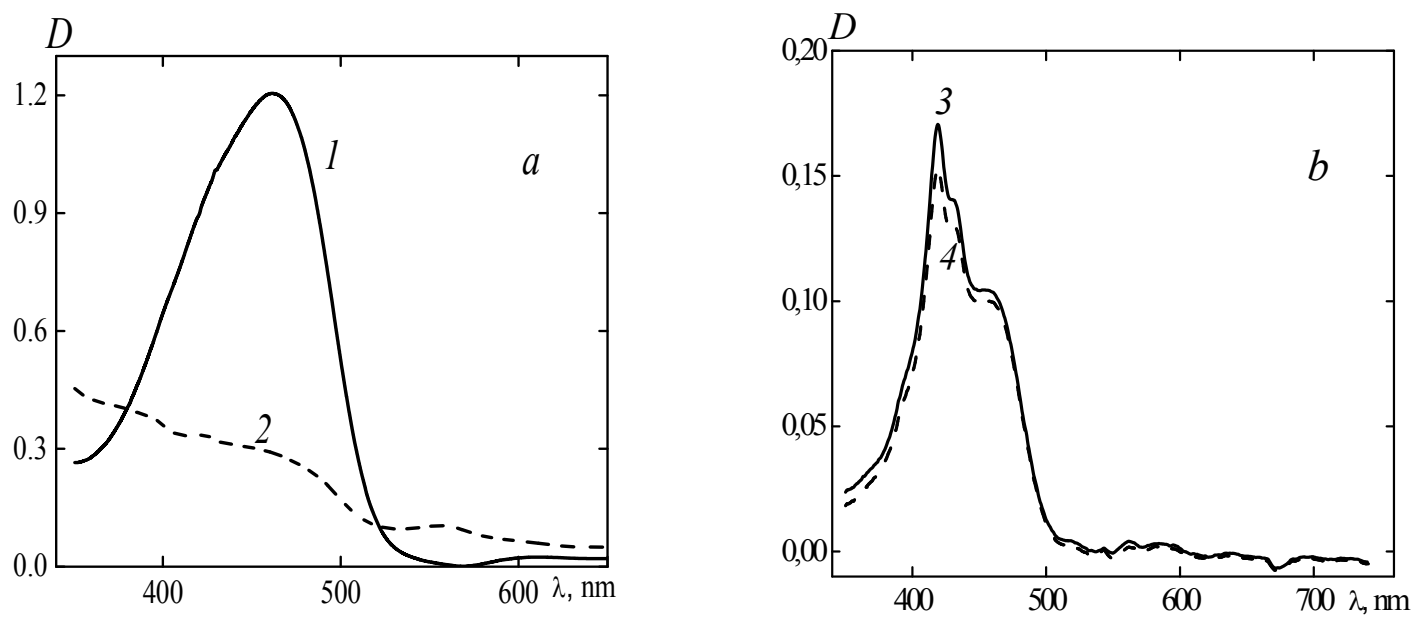

Fig. 3. Absorption spectra of bilirubin in medium (a) and a DMSO solution (b) after extraction from the cells without exposure (curves 1 and 3 ) and after exposure to radiation at $\lambda=465 \mathrm{~nm}$, power density $\mathrm{P}=20 \mathrm{~mW} / \mathrm{cm}^{2}$ for $\mathrm{t}=5 \min$ (curves 2 and 4 ). 
It was shown that exposure to radiation of LED sources of an emission band maximum at $465 \mathrm{~nm}$, corresponding to the spectral absorption maximum of bilirubin where almost complete photodestruction of bilirubin could be caused in the nutrient media, practically does not cause photolysis of the bilirubin localized in the mitochondria (Fig. 3). The findings suggest that the bilirubin has a high photochemical stability in the lipid environment. The possible causes of increased bilirubin photostability at its intracellular localization may be: a) the formation of tetrapyrrole dimeric forms, along with the monomers; b) the presence of closely located antioxidants; c) slow diffusion of oxygen involved in the reaction self-sensitized discoloration of the pigment; d) quenching of the triplet state of bilirubin by other biomolecules.

\section{CONCLUSION}

It is shown that bilirubin located within cells is characterized by high photochemical stability and it can act as a photo-sensitizer, causing photo-damaging lethal effect on animal cells in culture. The exposure to radiation of LED sources of an emission band maximum at about $465 \mathrm{~nm}$ and $520 \mathrm{~nm}$ causes substantially identical damaging effects on animal cells in culture that may be due to a significant change in the spectral characteristics of bilirubin upon entering into the cells. Bilirubin localized in the animal cells can perform the function of a selective filter to screen the radiation capable of causing potentially photo-isomerization of bilirubin bound to albumin molecules. The addition of sodium azide to the irradiated system and the quenching of singlet oxygen reduce the biological effect that points to the decisive role of singlet oxygen in the mechanism of photodynamic action sensitized with bilirubin.

\section{REFERENCES}

[1] T. Xiong, Y. Qu, S. Cambier, D. Mu, Eur. J. Pediatr. 170 (2011) 1247-1255.

[2] V. Yu Plavskii, V. A. Mostovnikov, A. I. Tretyakova, G. R. Mostovnikova, JAS. 75, (2008) pp. 383-394.

[3] F. Böhm, F. Drygalla, P. Charlesworth, K. Böhm, T. G. Truscott, K. Jokiel, Photochem. Photobiol. 62 (1995) 980-983.

[4] J. Oláh, E. Tóth-Molnár, L. Kemény, Z. Csoma. Brit. J. Dermatol, 169 (2013) 243-249.

[5] K. Tanaka, H. Hashimoto, T. Tachibana, H. Ishikawa, T. Ohki, Pediatr. Surg. Int. 24 (2008) 837-842.

[6] G. S. Liu, H. Wu, B. Q. Wu, R. Z. Huang, L. H. Zhao, Y. Wen, World J. Pediatr. 4 (2008) 31-35.

[7] V. Yu Plavskii, Nova Science Publishers Inc (New York), Edit by J. F. Novotny and F. Sedlacek, 2012, pp. 1-65.

[8] M. J. Maisels, A. F. McDonagh, N. Engl. J. Med. 358 (2008) 920-928.

[9] L. A. Stokowski, Adv. Neonatal Care (2006) 303-312.

[10] V. Yu Plavskii, A. I. Tretyakova, G R Mostovnikova, J. Opt. Technol. 81 (2014) 51-62.

[11] V. Yu Plavskii, A. I. Tretyakova, A. V. Mikulich, L.G. Plavskaya, Innovative Technologies in medicine. 2 (2014) 84-98.

[12] G. L. Landen, Y. T. Park, D. A. Lightner, Tetrahedron. 39 (1983) 1893-19071.

[13] L. Chuniaud, M. Dessante, F. Chantoux, J.P. Blondeau, J. Francon, F. Trivin, Clin. Chim. Acta. 256 (1996) 103-114.

[14] E, Akin, B. Clower, R. Tibbs, J. Tang, J. Zhang, Brain Res. 931 (2002) 168-175.

[15] P. Keshavan, S. J. Schwemberger, D. L. Smith, G. F. Babcock, S. D. Zucker, Int. J. Cancer. 112 (2004) $433-445$. 